\title{
Aspectos clínicos e laboratoriais da mastite induzida por inoculação intramamária de Staphylococcus aureus em vacas e búfalas
}

\author{
[Clinical and laboratory aspects of mastitis induced by intramammary inoculation of \\ Staphylococcus aureus in cows and buffaloes] \\ A.M. Lazzari ${ }^{1}$, M.V.S. Oliveira $^{2}$, B. Moreti
A. G. Guimarães
A.J. Fe Fesquita $^{4}$, J.P. Neves \\ ${ }^{1}$ Aluna de pós-graduação - Universidade de Brasília - UnB - Brasília, DF \\ ${ }^{2}$ União Pioneira de Integração Social - UPIS - Brasília, DF \\ ${ }^{3}$ Alunos de graduação - Upis, Brasília, DF \\ ${ }^{4}$ Universidade Federal de Goiás - UFG - Goiânia, GO \\ ${ }^{5}$ Universidade de Brasília - UnB - Brasília, DF
}

\begin{abstract}
RESUMO
Vários aspectos relacionados à mastite bubalina precisam ser esclarecidos. Muitas condutas são adaptadas a essa espécie pelo conhecimento adquirido com a espécie bovina. Com este experimento, objetivou-se evidenciar particularidades da mastite em búfalas e vacas que tiveram uma glândula inoculada com 1,0 x $10^{3}$ UFC de $S$. aureus. Os animais foram monitorados por cultura bacteriana do leite, California Mastitis Test (CMT), e escores para avaliação da severidade da mastite. Foram utilizados os seguintes critérios: temperatura retal, apetite, produção de leite (resposta sistêmica à inflamação), contagem de células somáticas (CCS), aparência/consistência da glândula e aparência da secreção láctea (resposta localizada à inflamação). Todos os animais desenvolveram mastite clínica superaguda. A bactéria foi recuperada de todas as glândulas desafiadas, sem diferença significativa no percentual de isolamento entre as espécies até o $11^{\circ}$ dia pós-inoculação, porém com diferença $(\mathrm{P}<0,001)$ no $30^{\circ}$ dia pós-inoculação. A CCS pelo método eletrônico e o CMT detectaram nas búfalas resposta mais intensa logo após a inoculação e diminuição mais rápida da contagem ao final do experimento, quando se comparou essa espécie com as vacas. Ambos os testes demonstraram correlação com a cultura bacteriana. Na avaliação da severidade da mastite, as médias do escore total, do escore da resposta local e do escore da resposta sistêmica foram mais elevadas na espécie bovina $(\mathrm{P}<0,05)$. Ao longo do período de observação, verificou-se uma capacidade superior das búfalas em recuperar o status sanitário adequado, chegando, ao final do experimento, com os parâmetros avaliados mais próximos dos fisiológicos.
\end{abstract}

Palavras-chave: bovino, bubalino, indução de mastite, S. aureus

\begin{abstract}
Several aspects related to bubaline mastits need to be clarified. Many conducts are adapted to this species by the knowledge adquired with the bovine species. This experiment aimed to evidence particularities of mastits in buffaloes and cows submitted to one-gland inoculation with $1.0 \times 10^{3} \mathrm{CFU}$ of S. aureus. The animals were monitored through bacterial culturing milk, California Mastitis Test (CMT) and scores to assess the severity of mastitis. The following criteria were used: rectal temperature, appetite, milk production (systemic response to inflammation), somatic cell count (SCC), appearance/consistency of the gland and appearance of the milk secretion (localized response to inflammation). All animals developed hyperacute clinical mastitis. The bacteria was recovered from all challenged glands, with no significant difference in the percentage of isolation between the species until day 11 after inoculation, but with a difference $(p<0.001)$ on day 30 post inoculation. The SCC with the electronic method and CMT, detected in buffaloes a more intense response right after the inoculation and a faster decrease of counting by the end of the experiment, when compared to cows. In both tests correlation with the bacterial culture was detected. In assessing the severity of mastitis, the averages of
\end{abstract}

Recebido em 3 de junho de 2013

Aceito em 19 de fevereiro de 2014

E-mail: lazzari@upis.br 


\section{Lazzari et al.}

total score, of the score of local response and the systemic response score were higher in the bovine species $(P<0.05)$. Throughout the observation period, there was a higher capacity of buffaloes in reaching the appropriate sanitary status, coming to the end of the experiment with the parameters closer to the physiological.

Keywords: bovine, bubaline, mastitis induction, S. aureus

\section{INTRODUÇÃO}

Staphylococcus aureus é considerado o agente etiológico mais prevalente das mastites bovina e bubalina. A mastite provocada por esse patógeno normalmente é subclínica, mas pode ser clínica, dependendo da dose infectante, da virulência da cepa e da resistência do hospedeiro. Elevação na CCS, diminuição de produção e modificações nos níveis de alguns componentes do leite estão presentes, independentemente da intensidade da resposta inflamatória (Tripaldi et al., 2010).

Esta bactéria é dotada de mecanismos de colonização e invasão, evasão, fatores que provocam danos ao tecido do hospedeiro, bem como de indutores/moduladores da resposta inflamatória (Gyles et al., 2010). A resposta do hospedeiro aos padrões moleculares associados ao patógeno e às toxinas superantigênicas é responsável pela resposta inflamatória, com efeitos locais e sistêmicos (Trabulsi e Alterthum, 2005). Esse fenômeno resulta em febre, aumento da permeabilidade vascular e recrutamento de leucócitos, importantes na defesa e na reparação tecidual, os quais, no entanto, também estão relacionados aos efeitos deletérios sobre o parênquima mamário e sobre os constituintes do leite. De uma forma geral, o dano ao tecido glandular mamário ocorre pelos fatores bacterianos e pelas reações imunes do hospedeiro (Zhao e Lacasse, 2008).

O interesse pela produção leiteira na espécie bubalina vem aumentando. Os conhecimentos existentes sobre as alterações locais e sistêmicas e evolução da mastite nesta espécie, são escassos, bem como são inconclusivas as informações sobre a utilização de parâmetros bovinos para o diagnóstico desse processo inflamatório em bubalinos (Amaral et al., 2005). Relatos indicam maior resistência da espécie bubalina à mastite em relação à bovina, e pesquisadores citam particularidades morfológicas, funcionais, químicas e celulares que seriam responsáveis por essa característica (Araújo e Gheller, 2005). Constituem objetivos a serem alcançados no presente experimento, avaliar o processo inflamatório e seus efeitos na glândula mamária de vacas e búfalas expostas ao mesmo patógeno, sob condições semelhantes de manejo e ambiente, e verificar a eficácia de alguns métodos no diagnóstico da mastite bubalina.

\section{MATERIAL E MÉTODOS}

Vinte fêmeas primíparas, 12 da espécie bubalina (raça Murrah) e oito da espécie bovina (Holandês x Zebu), livres de alterações clínicas e infecções nas glândulas mamárias, com um a dois meses de lactação, foram amostradas e observadas por um período de 33 dias. O experimento foi realizado em duas etapas, pré (Dia 1 a D3) e pósinoculação (D4 a D33). As seguintes avaliações foram realizadas de D1 a D14: caneca telada, CMT, CCS, cultura bacteriológica do leite, contagem de $S$. aureus no leite e avaliação clínica local e sistêmica. No D33 (30 dia pósinoculação), foi realizada avaliação clínica local e coleta de leite para cultura bacteriológica.

O isolado bacteriano inoculado foi o SBP 09/10, amostra de campo obtida de vacas com mastite, e a preparação do inóculo foi efetuada segundo a descrição de alguns pesquisadores, com modificações (Bannerman et al., 2004; Almeida et al., 2005; Martins Filho et al., 2007). A bactéria liofilizada foi inoculada em Brain Heart Infusion e incubada a $37^{\circ} \mathrm{C}$ por 15h. Posteriormente, $1 \mathrm{~mL}$ desse inóculo foi adicionado a $9 \mathrm{~mL}$ de água peptonada $0,1 \%\left(10^{-1}\right)$ e, assim, sucessivamente, até a diluição $10^{-4}$. Alíquotas de cada diluição foram utilizadas para contagem de unidades formadoras de colônias (UFC). Uma alíquota de $100 \mu \mathrm{L}$ da diluição $10^{-4}$ foi adicionada a $5 \mathrm{~mL}$ de salina esterilizada 0,85\%, alcançando, nesse volume total, aproximadamente $1,0 \times 10^{3}$ UFC do S. aureus. No D3, a glândula anterior esquerda (AE) de todos os animais foi inoculada com $5 \mathrm{~mL}$ de salina contendo $1,0 \times 10^{3} \mathrm{UFC}$, e a contralateral (AD) com $5 \mathrm{~mL}$ de salina esterilizada $0,85 \%$ (controle). 
As coletas de leite para cultura foram diárias, de todas as glândulas, após realização dos testes de caneca telada e CMT. No período pósinoculação, as amostras de leite da glândula AE foram utilizadas adicionalmente para contagem de S. aureus.

Nos dias D1 e D2 (pré-inoculação) e D4, D6, D8, D10, D12 e D14 (pós-inoculação), a glândula AE foi ordenhada completamente para a realização da CCS pelo método eletrônico. A CCS foi realizada pelo método de citometria de fluxo utilizando-se o equipamento Fossomatic 5000 Basic ${ }^{\circledR}$ (FOSS Eletric A/S. HILLEROD, Denmark), calibrado com leite bovino.

A resposta sistêmica à inflamação foi avaliada por alterações nos parâmetros apetite, temperatura retal e produção da glândula AE. A resposta localizada à inflamação foi verificada pela aparência/consistência da glândula, aparência da secreção láctea e CCS (Tab. 1).

Tabela 1. Critérios utilizados para avaliar a severidade da mastite em vacas e búfalas pósinoculação intramamária de $S$. aureus (SBP 09/10) na glândula AE

\begin{tabular}{|c|c|c|}
\hline Variáveis & Critérios & Escores \\
\hline \multirow{3}{*}{$\begin{array}{l}\text { Temperatura retal } \\
\left({ }^{\circ} \mathrm{C}\right)\end{array}$} & até 39,1 & 0 \\
\hline & $39,2-39,5$ & 1 \\
\hline & $\geq 39,6$ & 2 \\
\hline \multirow[t]{5}{*}{ Produção de leite } & sem queda & 0 \\
\hline & $\leq 20 \%$ & 1 \\
\hline & $21-40 \%$ & 2 \\
\hline & $41-60 \%$ & 3 \\
\hline & $\geq 61 \%$ & 4 \\
\hline \multirow[t]{3}{*}{ Apetite } & normal/fisiológico & 0 \\
\hline & comeu pouco & 1 \\
\hline & não comeu & 2 \\
\hline \multirow{3}{*}{$\begin{array}{l}\text { Condição da } \\
\text { glândula }{ }^{1}\end{array}$} & normal/fisiológica & 0 \\
\hline & edemaciada & 1 \\
\hline & lesão ulcerativa ${ }^{2}$ & 2 \\
\hline \multirow{3}{*}{$\begin{array}{l}\text { Aparência da } \\
\text { secreção láctea }\end{array}$} & normal/fisiológica & 0 \\
\hline & cor normal/grumos & 1 \\
\hline & cor alterada/seroso & 2 \\
\hline \multirow[t]{3}{*}{ CCS } & negativo & 0 \\
\hline & indeterminado & 1 \\
\hline & suspeito & 2 \\
\hline
\end{tabular}

Arq. Bras. Med. Vet. Zootec., v.66, n.5, p.1299-1307, 2014
Escores foram utilizados para graduar alguns aspectos avaliados e mensurar o grau de severidade da mastite (Tab. 1). Esse sistema de escores foi baseado no estudo de Atalla et al. (2009), com modificações. Para interpretação da CCS, foi utilizada a classificação empregada pela Rede Brasileira de Laboratórios de Controle da Qualidade do Leite credenciados ao Ministério da Agricultura na análise da qualidade do leite bovino cru refrigerado. Para o CMT, utilizaram-se cinco escores (negativo; traços; $1+$; $2+$ e $3+)$.

Foi realizada análise de correlação de Pearson para determinar o grau de associação entre as variáveis. Os dados de cultura bacteriana foram analisados por meio da análise de variância, e as médias comparadas pelo teste de Tuckey. As diferenças entre os resultados das respostas sistêmicas e das respostas localizadas foram analisadas por meio do teste do qui-quadrado. Todas as análises estatísticas foram realizadas usando-se o software STATISTICA, versão 8.

O comitê de ética das Faculdades Integradas da União Pioneira de Integração Social (Upis) aprovou o protocolo deste estudo experimental (Protocolo $\mathrm{n}^{\mathrm{o}}$ 005/10).

\section{RESULTADOS E DISCUSSÃO}

A inoculação de aproximadamente $1,0 \times 10^{3}$ UFC de $S$. aureus induziu mastite clínica superaguda em todos os animais. O patógeno foi recuperado de todas as glândulas desafiadas, e as glândulas controle permaneceram livres de infecção. Não foi observada diferença entre as duas espécies para o percentual de positividade à cultura bacteriana, nos dias D4 a D14. Quando esta mesma análise foi realizada considerando apenas D33 (o $30^{\circ}$ dia pós-inoculação), houve diferença $(\mathrm{P}<0,001)$, sendo o percentual de bovinos positivos de $50 \%$ e de bubalinos de $8,33 \%$. A análise da contagem de $S$. aureus no leite evidenciou que não houve diferença estatística entre a contagem de UFC/mL de vacas e búfalas.

A literatura cita diferentes números de UFC de $S$. aureus inoculados em vacas, com diferentes intensidades de resposta inflamatória, porém, em búfalas, essas informações não foram encontradas. Indução de mastite subclínica foi obtida por Martins Filho et al. (2007), utilizando 
500 UFC. Foi desencadeada mastite clínica em vacas Holandesas utilizando-se 74 UFC (Bannerman et al., 2004) e 5.000 UFC (Atalla et al., 2009), bem como casos clínicos e subclínicos por inoculação de 10.000 UFC (Petzl et al., 2008). Almeida et al. (2005) induziram mastite clínica em vacas mestiças (Holandês x Zebu) com 10.000 UFC, com recuperação da bactéria inoculada de todos os animais.

No presente experimento, foi instituído tratamento antimicrobiano intramamário (D6, D7 e D8) em todas as glândulas inoculadas com a bactéria para evitar exacerbação das manifestações clínicas. $\mathrm{O}$ tratamento foi realizado com 250mg de gentamicina (Gentocin ${ }^{\circledR}$ - Coopers, distribuído por Clivapec, Presidente Prudente, SP, Brasil), que in vitro demonstrou ação satisfatória.

Atalla et al. (2009) detectaram eliminação intermitente e cíclica de patógenos no leite de vacas com mastite. Esse fenômeno e a resposta diferenciada ao tratamento antimicrobiano poderiam explicar a diferença entre os percentuais de isolamento em D33, entre as duas espécies. Diferenças imunológicas também poderiam estar envolvidas. Pesquisadores detectaram particularidades na espécie bubalina que dificultariam a permanência do patógeno, como maior concentração de lactoferrina e lisozima (Sahoo et al., 1998) e 23\% mais lactoperoxidase que o leite de vaca (Kumar e Bathia, 1994).

Tolerância e resistência são duas estratégias distintas que conferem aos animais a capacidade de combater o patógeno. Segundo Detilleux (2011), essas estratégias podem apresentar diferenças em decorrência da dinâmica evolutiva. $\mathrm{O}$ patógeno inoculado no experimento em questão foi isolado de casos de mastite bovina. Pode-se sugerir uma adaptação maior da bactéria a esta espécie animal ou ainda uma intolerância maior da espécie bubalina em relação ao isolado utilizado, o que poderia estar contribuindo para a maior persistência do $S$. aureus no tecido glandular mamário bovino.

No D4 (primeiro dia pós-inoculação), 87,5\% (7/8) dos quartos mamários das vacas e 91,6\% (11/12) dos quartos mamários das búfalas, inoculados com $S$. aureus, apresentaram reação ao CMT. A reação foi menos intensa nas vacas do que nas búfalas, que apresentaram um percentual de CMT 3+ duas vezes maior $(75 \%)$ $(\mathrm{P}<0,05)$. No D5, todos os animais apresentaram reação inflamatória detectável por esse teste, e as vacas mantiveram esse perfil até o D14. Nesse dia, não houve diferença entre os percentuais de CMT 3+ $\left(\right.$ Freq $\left._{\text {média }}=54 \%\right)$, contudo houve diferença nos resultados negativos entre as duas espécies $(\mathrm{P}<0,05)$, bovinos com nenhum resultado negativo ao CMT e bubalinos com $50 \%$. Nas vacas, resultados semelhantes foram relatados por Martins Filho et al. (2007), que observaram $62 \%, 100 \%$ e $100 \%$ de reação, respectivamente, $24 \mathrm{~h}, 48 \mathrm{~h}$ e 11 dias pósinoculação de 500 UFC de $S$. aureus.

A CCS foi realizada nos dias D1 e D2 (préinoculação), D4 (primeiro dia pós-inoculação) e, posteriormente, a cada dois dias (até D14) (Tab. 2).

Tabela 2. Distribuição das amostras de leite da glândula AE de acordo com a espécie (frequência, \%), CCS e dias de coleta, considerando-se $<200.000$ como negativo, entre 200.000 - 300.000 como indeterminado e $>300.000$ como suspeito

\begin{tabular}{lcccccccc}
\hline \multirow{2}{*}{ Amostra } & \multicolumn{7}{c}{ Dias } \\
\cline { 2 - 9 } & 1 & 2 & 4 & 6 & 8 & 10 & 12 & 14 \\
\hline Vaca & $\mathrm{N}=8$ & $\mathrm{~N}=8$ & $\mathrm{~N}=8$ & $\mathrm{~N}=4$ & $\mathrm{~N}=4$ & $\mathrm{~N}=4$ & $\mathrm{~N}=5$ & $\mathrm{~N}=4$ \\
\hline$<200.000$ & 100,00 & 100,00 & 0,00 & 0,00 & 0,00 & 0,00 & 0,00 & 0,00 \\
$200.000-300.000$ & 0,00 & 0,00 & 0,00 & 0,00 & 0,00 & 0,00 & 0,00 & 0,00 \\
$>300.000$ & 0,00 & 0,00 & 100,00 & 100,00 & 100,00 & 100,00 & 100,00 & 100,00 \\
\hline Búfala & $\mathrm{N}=12$ & $\mathrm{~N}=12$ & $\mathrm{~N}=12$ & $\mathrm{~N}=8$ & $\mathrm{~N}=8$ & $\mathrm{~N}=7$ & $\mathrm{~N}=9$ & $\mathrm{~N}=10$ \\
\hline$<200.000$ & 100,00 & 100,00 & 0,00 & 0,00 & 0,00 & 0,00 & 11,11 & 20,00 \\
$200.000-300.000$ & 0,00 & 0,00 & 0,00 & 0,00 & 0,00 & 0,00 & 11,11 & 30,00 \\
$>300.000$ & 0,00 & 0,00 & 100,00 & 100,00 & 100,00 & 100,00 & 77,78 & 50,00 \\
\hline
\end{tabular}


Observou-se um aumento $(\mathrm{P}<0,05)$ na CCS após a inoculação tanto em vacas quanto em búfalas. No D4, apesar de todos os animais apresentarem contagens superiores a $300.000 \mathrm{CS} / \mathrm{mL}$, a contagem nas búfalas foi maior que a contagem nas vacas $(\mathrm{P}<0,001)$, porém percebeu-se a maior persistência da resposta inflamatória nas vacas, com diferença no D14 (P<0,01) (Tab. 2).

As células somáticas combatem o microorganismo invasor e reparam os tecidos danificados. A presença de altas contagens demonstra estimulação e liberação de citocinas com migração de leucócitos e tecido danificado que precisa ser reparado (Abbas e Lichtman, 2007). Pôde-se constatar neste estudo que, entre vacas e búfalas, não houve diferença significativa nas culturas de leite e na contagem bacteriana até o D14, porém houve diferença nos resultados de CMT e CCS. As búfalas reagiram mais intensamente aos testes após a indução, porém com uma menor persistência. Estes resultados sugerem diferenças na estimulação e/ou na ação de citocinas ou diferenças no grau de tecido glandular danificado pelo $S$. aureus.

A cinética das células somáticas analisadas pelo CMT e pela contagem eletrônica foi comparada. Observou-se a correlação entre os dois testes que teve sua significância confirmada pela análise estatística $(\mathrm{P}<0.001)(\mathrm{r}=0,90$ para as vacas e $\mathrm{r}=94$ para as búfalas). Foi realizado o teste de correlação de Pearson entre o percentual de positivos para cultura bacteriana e o percentual de positivos pelos testes CMT e CCS. Ambos os testes apresentaram correlação com a cultura bacteriana $(\mathrm{P}<0,001)$. Ao CMT, o coeficiente de correlação foi de 0,56 para as vacas e de 0,48 para as búfalas, e à CCS, de 0,68 para as vacas e de 0,70 para as búfalas. Comparando-se os coeficientes de correlação das duas espécies, não foi observada diferença entre os valores.

O método mais utilizado para detecção da mastite subclínica nas diferentes espécies animais é a mensuração de CS, e os resultados encontrados nesse trabalho revelaram uma associação entre cultura do leite, CMT e CCS. Essa associação já foi amplamente estudada em vacas e apresenta divergências nos trabalhos realizados em búfalas. Trabalho desenvolvido por Carvalho et al. (2007) indicou que o CMT não é um bom teste para detecção de mastite em bubalinos. Jorge et al. (2005) encontraram correlação positiva e significativa entre CCS e CMT, que também foi detectada no presente experimento, e Moroni et al. (2006) encontraram uma especificidade de $100 \%$ e uma sensibilidade de $99,1 \%$ entre contagem eletrônica de células somáticas e cultura de leite. Reza et al. (2011) descreveram uma sensibilidade do CMT para bubalinos de $70 \%$ na detecção de patógenos principais da mastite.

Tanto a CCS quanto os parâmetros aparência da secreção láctea e aparência/consistência da glândula foram utilizados para avaliar a resposta localizada à inflamação. Nos dias que precederam a indução, todas as glândulas encontravam-se livres de qualquer alteração nesses parâmetros (Fig. 1).

A aparência da secreção láctea foi avaliada por meio do emprego da caneca telada e a aparência/consistência da glândula por visualização e palpação. Alterações foram observadas, respectivamente, no primeiro e segundo dias pós-inoculação, em 12,5\% das vacas e $16,6 \%$ das búfalas. Nas vacas, alteração máxima da secreção láctea foi detectada nos dias D8 e D12, e nas búfalas, no D7. No D14, 75\% das vacas e $33,3 \%$ das búfalas encontravam-se com alterações visuais na secreção, verificandose diferença entre as duas espécies $(\mathrm{P}<0,05)$. Almeida et al. (2005) e Petzl et al. (2008) também detectaram alterações visuais no leite no primeiro dia pós-inoculação, em vacas, de 10.000 UFC de $S$. aureus.

Ao analisar-se as características da secreção, foram considerados três escores (Tab. 1). O escore 3 foi aplicado à alteração mais severa. $\mathrm{O}$ percentual de animais que apresentou esse escore foi diferente entre as espécies $(\mathrm{P}<0,05)$, sendo detectado em $57,97 \%$ e $37,03 \%$ das amostras de leite que demonstraram alteração visual, respectivamente, em vacas e búfalas. Ao longo do período experimental, todas as vacas apresentaram consistência alterada de glândula, e, até o D14, um animal apresentou lesão ulcerativa serossanguinolenta que evoluiu para purulenta. Avaliação realizada no D33 (30 dia pós-inoculação) revelou um segundo animal com lesão semelhante. $O$ percentual máximo de búfalas com alteração de aparência/consistência foi de $83,3 \%$, e nenhuma desenvolveu lesão ulcerativa. 
A aparência do leite e a aparência/consistência da glândula estão relacionadas a danos do tecido glandular mamário e/ou alterações no endotélio vascular, que dependem dos fatores de virulência da bactéria e reações imunes do hospedeiro (Zhao e Lacasse, 2008). As principais alterações observadas nas glândulas inoculadas foram edema e lesões ulcerativas, que não são comuns em mastites provocadas por S. aureus. A bactéria inoculada era grande produtora de alfa-toxina e apresentava o superantígeno SED (enterotoxina estafilocóccica do tipo D). Alfa-toxina induz a formação de poros em células do epitélio mamário e consequente liberação de mediadores inflamatórios, situação exacerbada pela presença do superantígeno (Sinha e Herrmann, 2005; Contreras e Rodrígues, 2011). Características da bactéria justificam as alterações encontradas nas glândulas infundidas, porém não explicam a maior gravidade observada na espécie bovina. Os resultados deste estudo revelaram que as búfalas recuperaram o aspecto fisiológico do leite com maior rapidez e apresentaram alterações mais brandas na glândula mamária, diferenças provavelmente justificadas pela reação imune do hospedeiro (Zhao e Lacasse, 2008).

Produção de leite, apetite e temperatura retal foram parâmetros utilizados para avaliar a resposta sistêmica à inflamação. Nas duas espécies animais, o peso do leite foi menor no período pós-inoculação $(\mathrm{P}<0,05)$. No $\mathrm{D} 4$, a queda foi mais perceptível nas búfalas $(\mathrm{P}<0,05)$. Nesse dia, $41,7 \%$ das búfalas e $25 \%$ das vacas apresentaram queda de até $20 \%$ (escore 1) da produção pré-inoculação. A queda mais acentuada nas búfalas persistiu até o D7 (terceiro dia pós-inoculação). As pesagens subsequentes revelaram leve recuperação na produção das búfalas e, no D14 do experimento, um animal havia recuperado sua produção original, 41,7\% apresentavam redução de até $20 \%$ (escore 1), e $25 \%$ redução superior a $61 \%$ (escore 4 ). Nas vacas, observou-se um comportamento diferente. Elas iniciaram com uma queda de produção mais branda, que foi se agravando ao longo do período de observação. Todas as vacas, no D14, apresentavam queda de produção, a maioria delas $(62,5 \%)$ com redução superior a $61 \%$ (escore 4) $(\mathrm{P}<0,05)$.

$\mathrm{O}$ apetite não se mostrou alterado no primeiro dia pós-inoculação. No D5, 50\% das vacas não se alimentaram (escore 2) durante a ordenha e
12,5\% apresentaram apetite diminuído (escore 1). Nesse dia, $50 \%$ das búfalas continuaram se alimentando adequadamente e o restante apresentou queda no apetite (escore 1). No D7 (terceiro dia pós-desafio), o apetite estava prejudicado em $62,5 \%$ das vacas e em $41,7 \%$ das búfalas. Nos dias subsequentes, até o D14, houve uma alternância de vacas e búfalas apresentando alterações no apetite.

Atalla et al. (2009) relataram que vacas desafiadas com 5.000 UFC de $S$. aureus apresentaram queda moderada e/ou severa de produção de leite. Bannerman et al. (2004) encontraram uma redução de $21 \%$ na produção de leite em vacas que tiveram uma glândula infundida com 74 UFC de $S$. aureus. Petzl et al. (2008) relataram queda de produção de $50 \%$ nas primeiras $12 \mathrm{~h}$, em vacas desafiadas com 10.000 UFC, com estabilização da produção em $70 \%$ do período pré-inoculação nas três semanas subsequentes. Todas essas induções foram realizadas em vacas da raça Holandesa.

A condição sanitária da glândula mamária interfere na produção de leite. Na mastite por $S$. aureus, a diminuição da função secretória ocorre, pois o patógeno, ao se aderir e multiplicar, produz substâncias citotoxigênicas que danificam o tecido mamário secretor; adicionalmente, enzimas oriundas de leucócitos provocam danos em células epiteliais da glândula (Akers e Nickerson, 2011). As vacas apresentaram nos parâmetros aparência/consistência da glândula e CCS maiores alterações quando comparadas às búfalas, e isto, provavelmente, justifica a queda mais acentuada de produção de leite.

A bactéria inoculada foi capaz de desencadear febre. Dois dias pós-inoculação (D5), a temperatura retal encontrava-se elevada em $100 \%$ das vacas e $83,3 \%$ das búfalas. A temperatura foi superior a $39,6^{\circ} \mathrm{C}$ (escore 2), em $87,5 \%$ das vacas e $80 \%$ das búfalas. Todas as vacas e $91,6 \%$ das búfalas alcançaram o escore máximo de temperatura no terceiro dia pósinoculação.

Bannermann et al. (2004) detectaram elevação de temperatura retal em vacas com mastite induzida por $S$. aureus a partir das $32 \mathrm{~h}$ pósinfecção. A temperatura máxima registrada foi de $39,4^{\circ} \mathrm{C}$, inferior à encontrada no presente experimento. Atalla et al. (2009) observaram, 
durante cinco dias, animais inoculados com $S$. aureus e registraram elevação de temperatura em $60 \%$ deles. Esse efeito sistêmico não foi detectado por Petzl et al. (2008) e por Martins Filho et al. (2007) pós-indução de mastite por inoculação de $S$. aureus.

A febre, um mecanismo importante no combate ao agente patogênico, é induzida por fatores de virulência presentes no patógeno (Trabulsi e
Alterthum, 2005). Em resposta a esses fatores, ocorre produção e liberação da citocina próinflamatória, interleucina-1 $\beta$, potente pirógeno endógeno (Watson et al., 2011).

A Fig. 1 mostra as médias do escore total em dias pré-determinados, em vacas e em búfalas. Foram representados graficamente somente os dias em que todos os parâmetros foram mensurados.
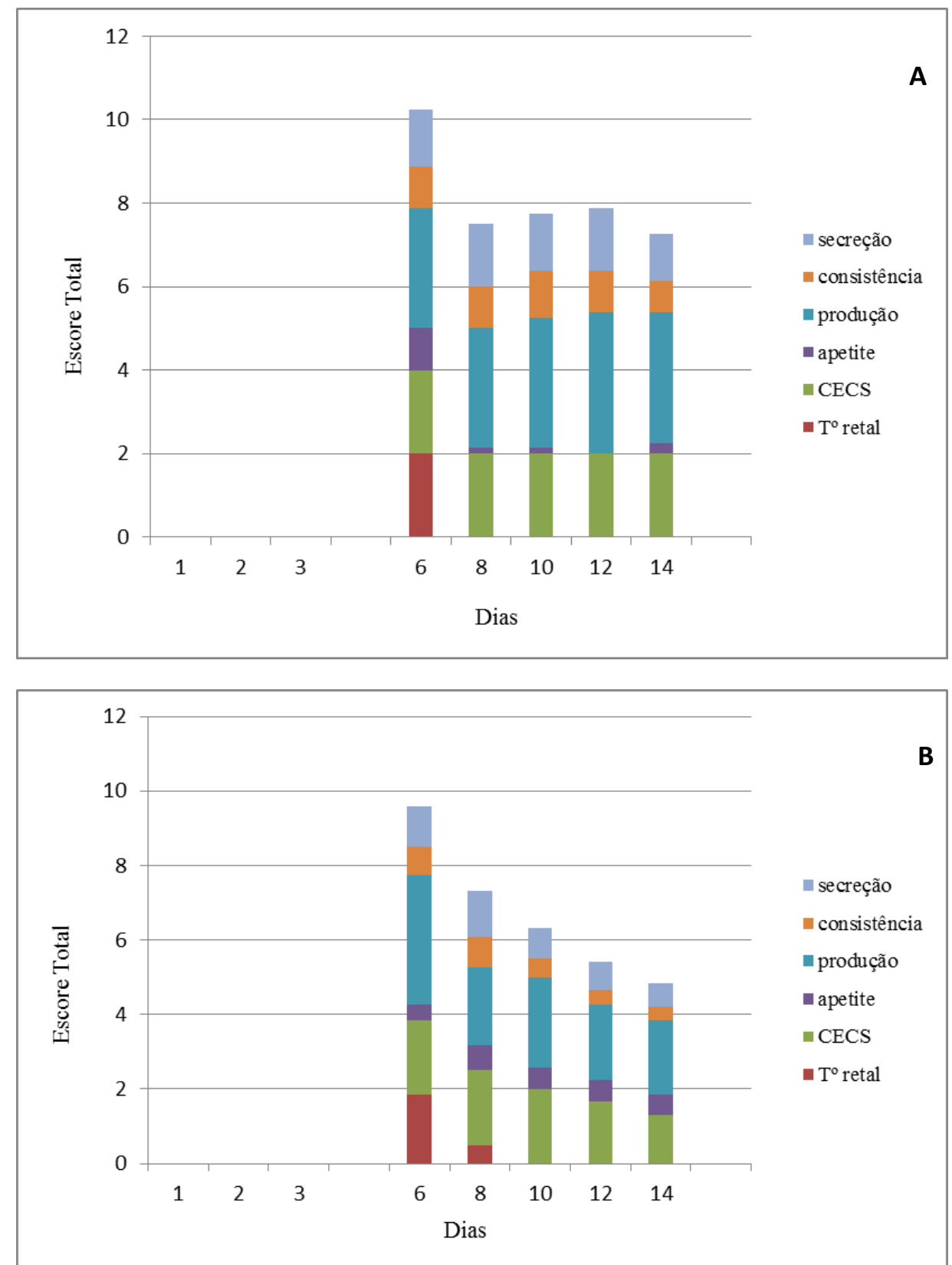

Figura 1. Médias do escore total bovino (A) e bubalino (B) pós-inoculação intramamária de $1,0 \times 10^{3}$ UFC de S. aureus (SBP 09/10) na teta AE de vacas e búfalas, em determinados dias do experimento. 
Nota-se, na referida figura, que o rebanho bovino ultrapassou o escore total 10 no terceiro dia pósinoculação (D6). Do D8 ao D14, percebe-se uma melhora constante no rebanho bubalino e uma persistência do quadro no rebanho bovino.

No D14, o escore total das vacas foi de 7,25 e das búfalas de 4,85 ( $\mathrm{P}<0,05)$. Nesse dia, um maior percentual de vacas apresentava contagens de CS superiores ao fisiológico, secreção láctea com aparência alterada e alteração na aparência/consistência da glândula. A temperatura retal, em ambas as espécies, encontrava-se dentro dos limites fisiológicos, o apetite encontrava-se alterado em um maior percentual de búfalas, e a produção da glândula AE diminuída em todo o rebanho bovino. Um maior percentual de vacas apresentava, nesse dia, redução superior a $61 \%$ da produção original da glândula AE. Ainda, houve diferença significativa $(\mathrm{P}<0,05)$ entre vacas e búfalas, no escore dos parâmetros da resposta localizada e da resposta sistêmica à inflamação.

Diferenças entre os resultados do presente experimento e aqueles dos pesquisadores anteriormente listados podem ser explicadas pela cepa e pela carga bacteriana empregadas na inoculação da glândula e por fatores inerentes aos animais utilizados, além da impossibilidade de comparação na espécie bubalina pela falta de referências. Diferenças na fisiopatologia da mastite foram detectadas entre as espécies bovina e bubalina, inoculadas com o mesmo isolado de $S$. aureus. Pesquisas são necessárias para elucidar os mecanismos responsáveis por tais diferenças.

\section{CONCLUSÕES}

A inoculação intramamária de aproximadamente $1,0 \times 10^{3}$ UFC de $S$. aureus (SBP 09/10) é capaz de provocar mastite clínica superaguda nas espécies bovina e bubalina, com maior persistência da bactéria na glândula mamária bovina e com resposta mais rápida e menos duradoura do processo inflamatório na espécie bubalina. Há diferenças na fisiopatologia da mastite entre as duas espécies pelas alterações locais e sistêmicas mais severas e persistentes na espécie bovina. As bubalinas apresentam maior velocidade de recuperação dos parâmetros de avaliação da resposta localizada à inflamação e da resposta sistêmica à inflamação, o que demonstra superioridade no combate ao agente infeccioso. Nas duas espécies, os testes de CMT e CCS apresentam correlação com a cultura bacteriana do leite.

\section{AGRADECIMENTOS}

À UPIS, por disponibilizar as búfalas e o local para o desenvolvimento do experimento; ao Laboratório de Bacteriologia do Departamento de Medicina Veterinária Preventiva da Universidade Federal de Santa Maria (UFSM), pelo isolamento e pela doação da bactéria inoculada; ao Laboratório de Enterotoxinas Estafilocócicas da Fundação Ezequiel Dias (MG), pela pesquisa do perfil enterotoxigênico e do potencial para produção de TSST-1 no $S$. aureus utilizado; e ao $\mathrm{CNPq}$, pelo auxílio no custeio.

\section{REFERÊNCIAS}

ABBAS, A.K.; LICHTMAN, A.H. Imunologia Básica. Funções e distúrbios do sistema imunológico. Rio de Janeiro: Elsevier, 2007. $354 \mathrm{p}$.

AKERS, R.M.; NICKERSON, S.C. Mastitis and its impact on structure and function in the ruminant mammary gland. J. Mammary Gland Biol. Neoplasia, v.16, p.275-289, 2011.

ALMEIDA, L.A.B.; BRITO, M.A.V.P.; BRITO, J.R.F. et al. Tratamento de mastite clínica experimental por meio de ordenhas múltiplas em vacas leiteiras inoculadas com Staphylococcus aureus. Arq. Inst. Biol., v.72, p.1-6, 2005.

AMARAL, F.R.; CARVALHO, L.B.; BRITO, J.R.F.; SILVA, N. Qualidade do leite de búfalas: contagem de células somáticas. Rev. Bras. Reprod. Anim., v.29, p.101-105, 2005.

ARAÚJO, D.K.G; GHELLER, V.A. Aspectos morfológicos, celulares e moleculares da imunidade da glândula mamária de búfalas (Bubalus bubalis): revisão de literatura. Rev. Bras. Reprod. Anim., v.29, p.77-83, 2005.

ATALLA, H.; GYLES, C.; WILKIE, B. et al. Somatic cell scores and clinical signs following experimental intramammary infection of dairy cows with a Staphylococcus aureus small colony variant ( $S$. aureus $\mathrm{SCV}$ ) in comparison to other bovine strains. Vet. Microb., v.137, p.326-334, 2009. 
BANNERMAN, D.D.; PAAPE, M.J.; LEE, J.W. et al. Escherichia coli and Staphylococcus aureus elicit differential innate immune responses following intramammary infection. Clin. Diagn. Lab. Immunol., v.11, p.463-472, 2004.

CARVALHO, L.B.; AMARAL, F.R.; BRITO, M.A.V.P. et al. Contagem de células somáticas e isolamento de agentes causadores de mastite em búfalas (Bubalus bubalis). Arq. Bras. Med. Vet. Zootec., v.59, p.242-245, 2007.

CONTRERAS, G.A.; RODRÍGUES, J.M. Mastitis: Comparative etiology and epidemiology. J. Mammary Gland Biol. Neoplasia, v.16, p.339-356, 2011.

DETILLEUX, J.C. Effectiveness analysis of resistance and tolerance to infection. Genet. Sel. Evol., v.43, p.1-10, 2011.

GYLES, C.L.; PRESCOTT, J.F.; SONGER, G.; THOEN, C.O. Pathogenesis of Bacterial Infections in Animals. 4.ed. Iowa: Blackwell, 2010. 643p.

JORGE, A.M.; ANDRIGHETTO, C.; STRAZZA, M.R.B. et al. Correlação entre o California Mastitis Test (CMT) e a contagem de células somáticas (CCS) do leite de búfalas Murrah. R. Bras. Zootec., v.34, p.2039-2045, 2005.

KUMAR, R.; BATHIA, K.L. Lactoperoxidase activity in buffalo milk and whey. In: WORLD BUFFALO CONGRESS, IV, 1994, São Paulo. Anais ... São Paulo: [s.n.] 1994. p. 168-170. (Resumo).

MARTINS FILHO, L.P.; VIDAL-MARTINS, A.M.C.; CESCO, F.T.R.S. et al. Indução experimental de mastite subclínica em vacas da raça Holandesa mediante inoculação intramamária de Staphylococcus aureus (estirpe ATCC 25923). Ars Vet., v.23, p.75-80, 2007.
MORONI, P.; ROSSI, C.S.; PISONI, G. et al. Relationships between somatic cell count and intramammary infection in buffaloes. J. Dairy Sci., v.89, p.998-1003, 2006.

PETZL, W.; ZERBE, H.; GÜNTHER, J. et al. Escherichia coli, but not Staphylococcus aureus triggers an early increased expression of factors contributing to the innate immune defense in the udder of the cow. Vet. Res., v.39, p.1-23, 2008.

REZA, V.H.; MEHRAN, F.M.; MAJID, M.S.; HAMID, M. Bacterial pathogens of intramammary infections in Azeri buffaloes of Iran and their antibiogram. AJAR., v.6, p.25162521, 2011.

SAHOO, G.; MORE, T.; SINGH, V.K. A comparative study on certain enzymes of the granulocyte from different ruminant species. Comp. Immunol. Microbiol. Infect. Dis., v.21, p.319-325, 1998.

SINHA, B.; HERRMANN, M. Mechanism and consequences of invasion of endothelial cells by Staphylococcus aureus. Tromb. Hemost., v.94, p.266-277, 2005.

TRABULSI, L.R.; ALTERTHUM, F. Microbiologia. 4.ed. São Paulo: Atheneu, 2005. $718 \mathrm{p}$.

TRIPALDI, C.; PALOCCI, G.; MIARELLI, M. et al. Effects of mastitis on buffalo milk quality. Asian Austra. J. Anim., v.23, p.1319-1324, 2010.

WATSON, C.J.; OLIVER, C.H.; KHALED, W.T. Cytokine signaling in mammary gland development. J. Reprod. Immunol., v.88, p.124129, 2011.

ZHAO, X.; LACASSE, P. Mammary tissue damage during bovine mastitis : causes and control. JAS, v.86, p.57-65, 2008. 